\title{
Research on the Bottleneck of Supply-chain Management in Construction Enterprises
}

\author{
Yifeng $\mathrm{Xu}$ \\ Administrative Engineering College, Zhengzhou University, Zhengzhou, China \\ 370778782@qq.com
}

Keywords: Supply-chain, Construction enterprise, Application, Bottleneck

\begin{abstract}
The construction industry as a pillar industry and the construction industry, occupies an important position in the national economic structure of China, accounting for about 7\% of GDP. The materials cost of the average expenditure of reaches $60 \%$, which has a great impact on the construction material management of construction enterprises. The profits of the supply chain management theory have been widely used in many fields. Especially in the field of manufacturing industry, to achieve the overall value maximization effect is very obvious. But from the project construction enterprise daily practice, few enterprises adopt supply chain management mode for construction materials management. Therefore, this paper studies the supply chain management application in the construction enterprise.

\section{INTRODUCTION}

The construction industry occupies an important position in the national economic structure in China, according to statistics released by the National Bureau of statistics of China, nearly five years of construction industry output value were 3.28,3.68,4.08,4.48,4.65 trillion RMB accounting for the same period of GDP $(6.78,6.89,6.94,7.04,6.87 \%$, data and pictures are from the statistical bulletin of the National Bureau of statistics $<2015$ of national economy and society the development of $>$ ) so the construction industry belongs to the pillar industry(National Bureau of statistics 2016).

According to the current composition of engineering cost, with nearly 5 years of completed project settlement, in the format of cost management system in the construction industry, the data is more recognized: the material cost in the construction industry about spending

of construction industry in 2015, rough statistics (construction enterprises) materials consumption reached 2 trillion and 790 billion RMB, the scale is huge. As shown below (Fig.1. \&Fig.2.)

At present, the implementation of the "headquarters procurement center or project material centralized purchasing management model of material costs and domestic consumption of the majority of large and medium-sized construction enterprises, the basic principle of this model is: the headquarters procurement center to co-ordinate regulation of subordinate material management business company and the level of the project department, project department and subsidiary level respectively(SINOHYDRO 2014). Have their own procurement department, responsible for the supplier survey, the selection, evaluation, assessment, contract management work. As shown below (Fig.3. The schematic diagram of material centralized purchasing mode)
\end{abstract} accounted for more than $60 \%$ of the gross output value

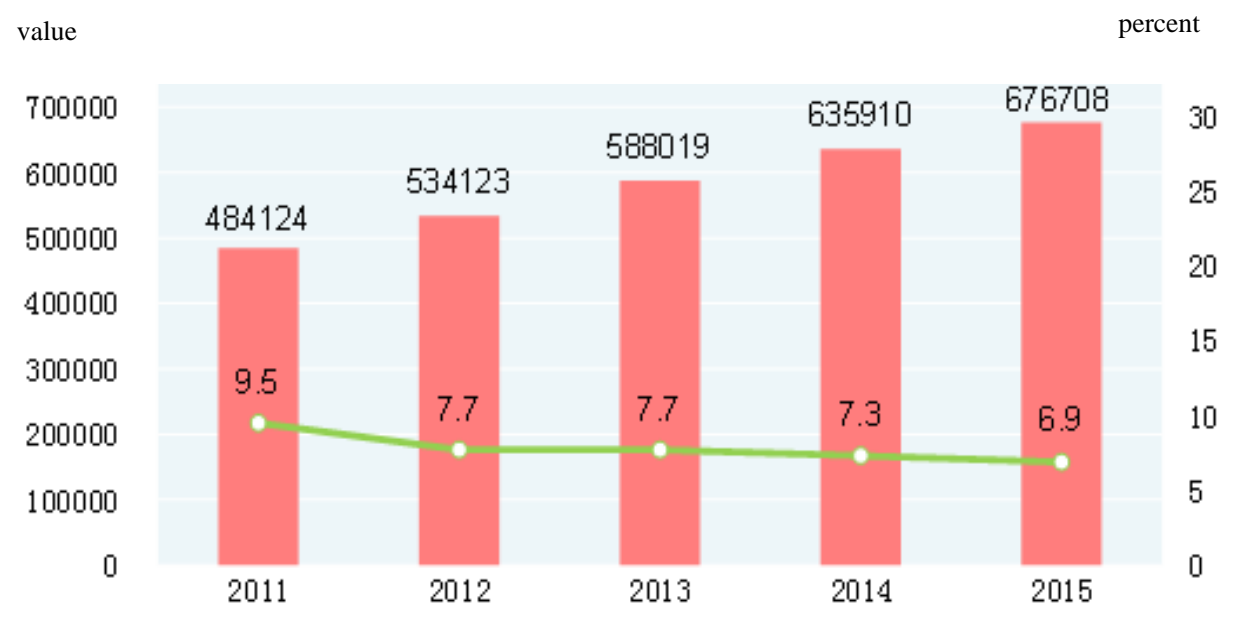

Fig.1. The added value of GDP and its growth rate(2011-2015) 


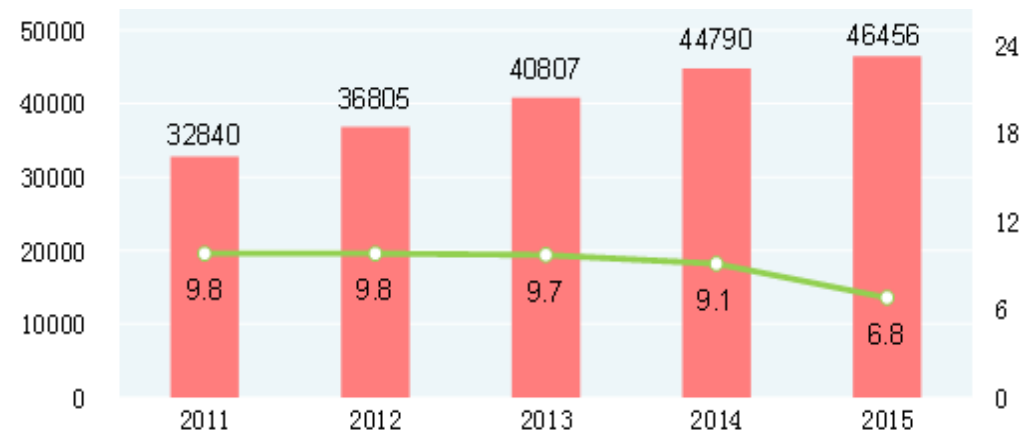

Fig.2. The added value of construction industry and its growth rate (2011-2015)

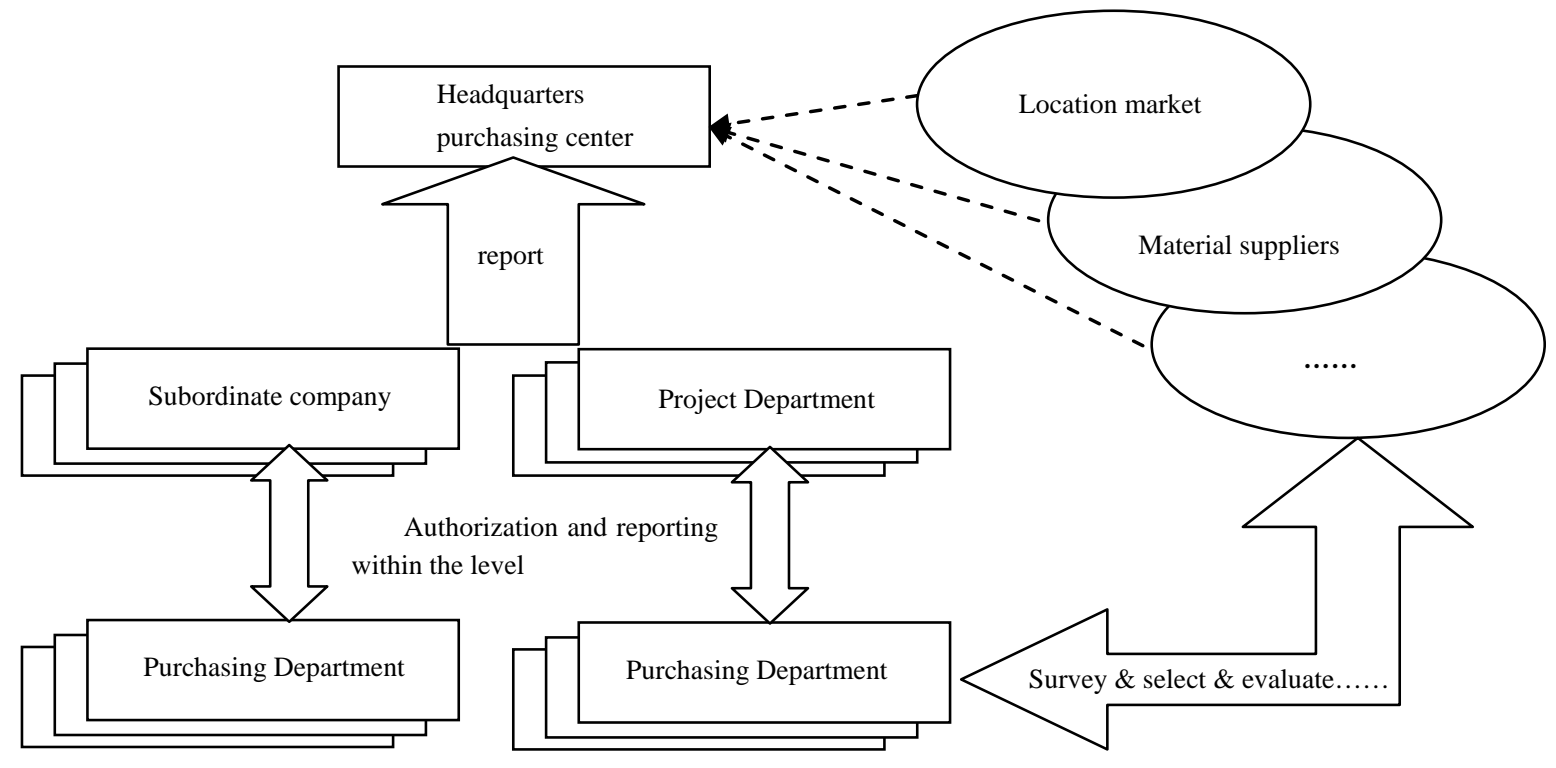

Fig.3. The schematic diagram of material centralized purchasing mode

\section{THE CHARACTERISTICS OF MATERIAL FLOW IN THE CONSTRUCTION INDUSTRY}

Different from industrial and manufacturing, material circulation in the construction industry is more special, mainly in the following aspects:

1st, form the product form with specific project unit, individuation characteristic is distinct

The product of the construction industry form as follows: a building, a building, a section of the road, a dam can play one or more functions of buildings, structures, different functional requirements embodied in existing technology under the conditions of different forms, personalized, unique features of two buildings is obvious. At the same time, even in the same construction within the district will be because of different positions, different geological conditions (Zhen Lin 2010), different construction sequence and there is a big difference.

2ed, a large number of materials required, a large number

According to incomplete statistics, required to complete a 22 storey residential building materials, equipment up to hundreds, even thousands. Even the relatively simple water conservancy and civil engineering, required materials, equipment and auxiliary facilities are also very diverse, a large number of simple earthwork engineering as an example light, not to consider the project itself involves material, excavation, transportation equipment, filling equipment, fuel, power supply, temporary production, living facilities and so on numerous is estimated to more than one hundred.

3rd, the material to the finished product circulation and transformation of the link is more, uncertain factors, change quickly

The construction completion of the product is a type of manufacturing system, not only the use of all kinds of materials, selection of process procedure, and many uncertain factors, change quickly. For example, in earthwork construction, soil water content rate of this material because of the weather, stacking time, transport distance and other factors change with the change. When construction should fully consider and adopt different processes (such as increasing drying, mixing water, etc.) to be adjusted. For example in the process of concrete construction, not only to consider the change of material characteristics, but also estimate the full impact of external temperature, humidity change, but also to consider the construction schedule, construction intensity a number of indicators of the impact on the overall product. (China Construction Supervision Association 2013)

4th, the organizational relationship is complex, the 
participants are numerous, and most of them are not continuous

The complicated forming process of construction products, from the owner (construction unit) the organization way, including at least the project construction units, design units, supervision units, construction and consulting unit, general contractor, equipment suppliers and subcontractors; directly from the organization (general contractor) approach, including the material supplier service supplier, supplier, equipment leasing, the project department, general contractors and so on. In addition to the contract organization, including supervision and supervision by the relationship, cooperation and coordination between the parallel and so on. Many parties involved, and most of all with the progress of the project and the stage of participation, without continuity. (Haigui Zhang 2012)

5 th, customers have high requirements for the quality, innovation, duration, cost and safety of construction products

The products of construction industry and other categories are essentially different and irreplaceable. Once the product is formed, the cost of the change is very high. Therefore, the customers have high requirements for the quality, innovation and cost of the construction products.

6th, the construction industry product formation cycle is long, the investment is huge

\section{CLASSIFICATION OF MATERIALS IN CONSTRUCTION INDUSTRY}

Because the construction industry in the direct material transactions are mostly concentrated in the construction enterprise side, how to effectively and economically to carry on the material classification management is a prominent issue facing most of the construction enterprises. Most of the previous economic weight of enterprises tend to focus on materials and to classify and manage them.

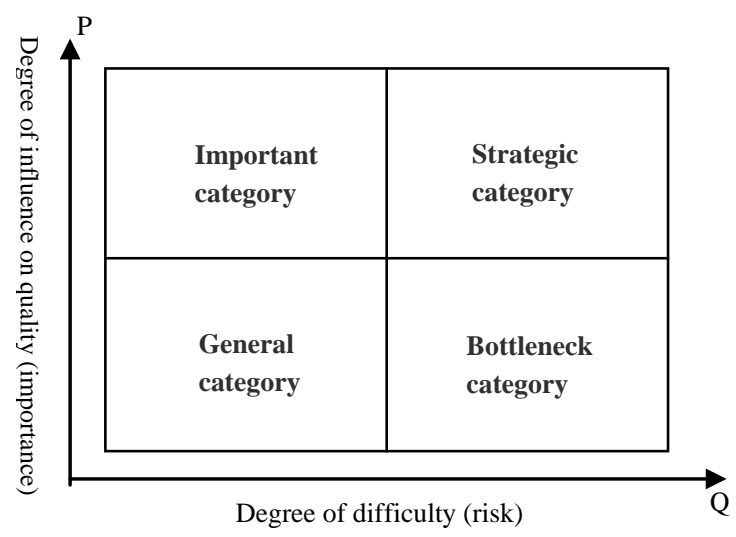

Fig.4.Material classification matrix

Considering the contribution of this classification method cannot fully reflect the construction unit profit problem, urgency and difficulty of material supply, while ignore the occupation of funds is not big, but the influence on the quality of a high degree of risk or the existence of supply material. (Pressey, A. Etc 2007)
According to the production of the construction industry, using qualitative analysis method combining the material classification matrix model the classification of building materials (White, A. 1999). As shown below (Fig.4. Material classification matrix):

\subsection{Strategic category}

Purchasing a large quantity, itself is expensive, occupied the capital, will have a significant impact on the quality of the project, the qualified supplier and not much to choose from (and even some belong to a single source procurement). This kind of materials including general elevator, air conditioning, fire prevention materials and equipment.

\subsection{Important category}

Purchasing a large quantity, itself is expensive, occupied the capital, will have a significant impact on the quality of the project, but the market supply is sufficient for a buyer's market, relatively easy to obtain. This kind of materials including steel, concrete, wood and so on.

\subsection{Bottleneck category}

Purchasing volume, its value is not too expensive, but more important to the unit, is a seller's market, is not easy to obtain. This kind of material is a new material and the owners specific materials, such as a new type of waterproof material, prestressed steel strand.

\subsection{General category}

Variety, the value is not high, less occupation of funds, this kind of material is easily available in the market, a small difference in general. Including sand, stone and other nearby raw materials, fuel, labor supplies, office supplies and so on.

\section{INFLUENCE THE BOTTLENECK PROBLEM OF SUPPLY CHAIN APPLICATION IN CONSTRUCTION ENTERPRISES}

\subsection{The lack of internal motivation of supply chain management in construction enterprises}

First, China implements the access management qualification of construction enterprises (i.e. construction enterprises must have a certain level of qualification, and then engaged in engineering construction in the corresponding level). At the same time, due to the existence of local protectionism, the construction enterprise has a relatively unique nature of monopoly, forming a more distinct local the enterprise level control and monopolize the local market atmosphere, rely on regional advantages to obtain benefits far outweigh the benefits of strengthening internal management (some companies even on the qualification certificate can obtain high income). Subcontracting, subcontracting is a common phenomenon, the actual operation personnel in a certain extent and has been seriously out of construction enterprises, resulting in enterprises in the system of top-level design, does not spontaneously to improve internal management level to consider (which 
can not consider, because most of the internal management has been outsourced).

Second, although in the bidding period, according to market competition form of construction product price. But as long as the construction contract, in the forming process of building products (construction), into a single source (-- there are few projects of construction enterprises, intermediate conversion) so that the various links because the management costs increase (note that contains the backward management of cost increases) to reflect the stage of construction material price adjustment, adjustment, and ultimately paid by the construction unit. This is the most domestic projects are one of the causes of the completion of the tender offer is considered more than phenomenon.

Third, in the bidding stage, the construction enterprise by the construction unit price bar (the highest closing price) limit, often using the unbalanced bidding strategy and quotation; once after winning, through changes to the project, change the replacement material means to adjust the corresponding low-cost project, improve the economic benefit. According to bid price formation to the foundation and motivation of supply chain management are very weak. In addition, the bidding stage of construction enterprises to participate in the personnel often are not involved in specific aspects of the implementation of the project, the project management personnel to carry out the lack of corresponding management perform.

\subsection{The application experience of the existing supply chain management is not very suitable for construction enterprises}

Although the text has been on building materials is analyzed, but the experience of the corresponding management application is not very suitable for the construction enterprises, the main reason is the change of the construction enterprise production site and production processes and the corresponding conditions continue to occur.

For example, in order to ensure that the project product supply bottlenecks, conventional companies can take to ensure inventory methods for construction enterprises is not universal in land area construction does not have the possibility of supporting the establishment of the warehouse; Other ways, in order to ensure the supply of goods, the establishment of partnerships or execution of production experience may for the construction enterprises also should discount in small and medium-sized city construction enterprises self mixing station is feasible, but for the big city or longterm projects, and projects to reach an agreement by the supplier but the supply may be more rational.

For the general category, in the development area around the city or the market, may not be a problem; but if the field in remote areas or wilderness, makes the management personnel must pay attention to the category of material procurement.

Even if a large company also has many projects in many places, but also because the difference between the regional differences, making the project materials needed for deployment, there is a big difference between the supply network and conventional supply chain network multi regional supply network design project. At one time, the diversity and heterogeneity of the material demand, resulting in two network there is essential difference. Therefore, often used in the conventional supply chain in the centralized batch purchasing, on-demand supply "experience do not rashly use.

\subsection{The concept of supply chain management, acceptance is not high in construction enterprises}

The construction industry is a labor-intensive enterprises, coupled with the impact of the traditional system, many enterprises have great inertia level management thought that now has been able to meet the needs of management system, change management mode there is a big uncertainty and may increase the cost, and refuses to change.

\section{CONCLUSIONS}

The construction industry occupies an important position in the national economy in China, under the background of economic globalization, great change in the whole society, the premise of transformation, can be expected to eventually break the barriers, the strange phenomenon does not comply with market rules in the existing environment will eventually disappear, the future construction enterprises will face the fierce market competition. Only enhance the core competitiveness of construction enterprises is the "benevolent" will become the new consensus building industry. In this process, with the further promotion of construction supply chain theory, "the implementation of supply chain management can effectively reduce the cost of" concept further accepted, believe that in the near future, supply chain management will be able to open in the building industry spreading.

\section{REFERENCES}

[1] China Construction Supervision Association 2013, information management of construction engineering. China Construction Industry Press, Beijing

[2] Haigui Zhang 2012, Project management in modern construction. Jindun Press, Beijing.

[3] National Bureau of statistics 2016, People's Republic of China 2015 national economic and social development statistical bulletin

[4] Pressey, A. Tzokas, N. Winklhofer, H. 2007, Strategic purchasing and the evaluation of "problem" key supply relationships: What do key suppliers need to know. Journal of Business \& Industrial Marketing, 22, 282-294

[5] SINOHYDRO 2014, Corporation internal management control manual (material and equipment Part)

[6] White, A. 1999, Value Chain Management, Collaboration and the Internet. Logiclity Inc., Atlanta.

[7] Zhen Lin 2010, Research on material management of construction site. Chinese urban economy, 6, 18-25. 